\title{
Utilization Technique of Inclusion to Improve Steel Property: 0xide Metallurgy
}

\author{
Keiji Nakajima ${ }^{1 *}$, Wangzhong $\mathrm{Mu}^{2}$ and Pär G Jönsson \\ ${ }^{1}$ Department of Materials Science and Engineering, KTH Royal Institute of Technology, Sweden \\ ${ }^{2}$ Department of Materials Science and Engineering, McMaster University, Canada
}

Submission: June 04, 2017; Published: June 19, 2017

*Corresponding author: Keiji Nakajima, Department of Materials Science and Engineering, KTH Royal Institute of Technology, Brinellvägen 23 , SE-10044, Stockholm, Sweden, Email: keiji.nakajima@gmail.com

Wangzhong Mu, McMaster Steel Research Centre, Department of Materials Science and Engineering, McMaster University, 1280 Main Street West, Hamilton, Ontario, Canada, Email: wangzhongmu@gmail.com

\begin{abstract}
Inclusion particle behaviors in liquid steel and in solid steel affect both of the cleanliness and the toughness of the steel materials. These fundamental techniques have been named as "Clean Steel" and "Oxide Metallurgy" respectively, and have utilized in practice. In recent years, the importance of oxide utilization technique, which is referred to as "Oxide Metallurgy," has been increased. Specifically, this review paper highlights the frontiers of experimental and theoretical investigations on the effects of inclusion characteristics on the IGF formation in lowalloy carbon steels by the current authors.

Keywords: : Inclusion; Intragranular ferrite; Microstructure; Property; Steel; Oxide metallurgy

Abbreviations: DSC: Differential Scanning Calorimetry; CCT: Continuous Cooling Transformation; IGF: Intragranular Ferrite; GBF: Grain Boundary Ferrite; HAZ: Heat Affected Zone; HT-CLSM: High Temperature Confocal Laser Scanning Microscope
\end{abstract}

\section{Introduction}

Non-metallic inclusion particles in steels are generally considered to be detrimental for the mechanical properties. However, certain kinds of non-metallic inclusions are recognized to act as potent nucleation sites for the formation of intragranular ferrite (IGF) in low-alloy carbon steels. This preferential formation of IGF reduces the amount of grain boundary ferrite (GBF) and hence, improves the toughness of the steel. This phenomenon occurs based on the concept of "Oxide Metallurgy" [1], which describes the correlation between inclusion, microstructure and mechanical property of the heat affected zone (HAZ) of steel weldment. The schematic illustration can be shown in Figure 1. With the development of this concept, it is found that not only oxides but also complex inclusions including nitrides [2] can act as the effective nucleation site to induce IGF formation. In order to perform the microstructure control based on the concept of "Oxide Metallurgy", the authors designed a special alloy by adding fine oxides or nitrides directly into the steel. This series work using the above special alloy has been subsequently reported in Refs. [2-11]. This paper briefly summarizes the novel aspects of experimental and theoretical studies on the effect of inclusion on the IGF formation, and aims to give a better control of improving the steel quality during casting and in the HAZ of weldment.

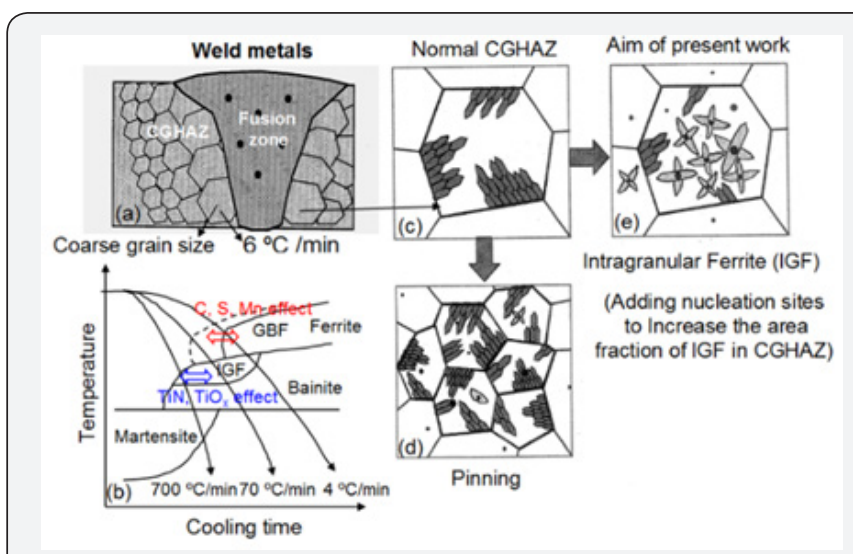

Figure 1: Schematic illustrations of (a) coarse grain heat affected zone (CGHZA), (b) concept CCT diagram, (c) GBF formation in CGHAZ, (d) pinning effect in CGHAZ and (e) IGF formation in CGHAZ. 


\section{Discussion}

\section{Experimental study}

The schematic illustration of experimental set-up to add oxides and nitrides powders into steel to investigate inclusion formation and microstructure characteristics according to "Oxide Metallurgy" is shown in Figure 2. The details have been reported by $\mathrm{Mu}$ et al. [3-6]. By using this method, the effects of inclusion composition and its size on IGF formation can be quantitatively investigated. It is reported that the complex TiN+Mn-Ti-Al-Si$\mathrm{O}+\mathrm{MnS}$ inclusion is a typical inclusion in a low-alloy carbon steel with TiN addition [3]. Also, $\mathrm{TiO}_{\mathrm{x}}+\mathrm{MnS}$ with small amount of glassy oxide is the typical inclusion formed in the low-alloy carbon steels with $\mathrm{Ti}_{2} \mathrm{O}_{3}$ and $\mathrm{TiO}_{2}$ additions [4-6]. According to the latest literature review by $\mathrm{Mu}$ et al. [2], it was summarized that the potency order can be as follows: $\mathrm{TiO}_{\mathrm{x}}(\mathrm{x}=1.5-1.7)>$ $\mathrm{TiO}_{\mathrm{x}}+\mathrm{MnS}>\mathrm{TiN}+\mathrm{Mn}-\mathrm{Si}-\mathrm{Al}-\mathrm{Ti}-\mathrm{O}+\mathrm{MnS}>\mathrm{V}(\mathrm{C}, \mathrm{N})+\mathrm{MnS}>\mathrm{VC}+\mathrm{MnS}$. Moreover, the authors can emphasis that the whole composition has no meaning when considering the inclusion characteristics related to IGF formation. Instead, the surface composition of the inclusion should be focused in order to investigate the mechanism of IGF formation, since the surface of inclusion is the actual nucleation site for IGF.

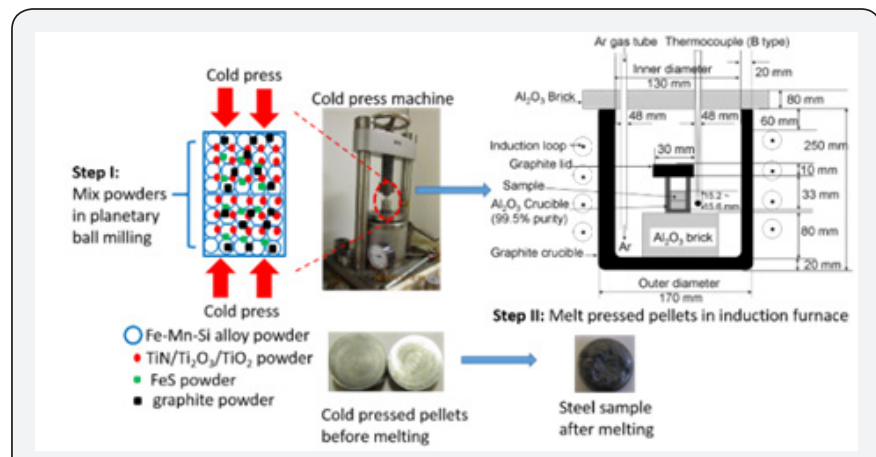

Figure 2: Schematic illustration of preparation method pf steel sample with TiN and Ti-oxides additions, which is done by the present authors.

By using the as-cast steel samples, the high temperature confocal laser scanning microscope (HT-CLSM) has been applied to the in-situ observation of IGF formation [7-8]. The contribution by the authors is to quantitatively investigate the effects of cooling rate and prior austenite grain size on IGF formation kinetics. Moreover, the HT-CLSM measurements in combination with the differential scanning calorimetry (DSC) measurements have been used to draw the schematic continuous cooling transformation (CCT) diagram of IGF and GBF formation. According to the authors' knowledge, this is the first trial to combine these two methodologies to draw CCT diagrams for the austenite decomposition process.

\section{Theoretical study}

Besides the experimental studies, the theoretical studies related to "Oxide Metallurgy" have been performed by the authors. Firstly, it is found that the equilibrium calculation method by using thermodynamic calculation software, such as ThermoCalc, is very useful to predict the composition and quantity of various inclusions formed during cooling process in actual multi-component steel [3-4], since the equilibrium calculation results can offer a good agreement with the experimental data. Moreover, the authors proposed a modified heterogeneous nucleation model to predict the possibility of IGF nucleation from a spherical shape nucleation site [9-10]. The contribution of this model is a quantitative evaluation of the energy barrier of IGF nucleation from different nucleation sites including TiO, TiN and VN, based on the interfacial energies between nuclei inclusions and austenite/ferrite. Also, the effect of different element contents of the steel matrix on IGF nucleation can also be quantitatively investigated using this model. Finally, the model calculation results show that the chemical part interfacial free energy without the misfit energy could offer a good agreement with experiment data.

\section{Conclusion}

"Oxide Metallurgy" is a novel technique to utilize fine inclusions to optimise the steel microstructure and improve the steel toughness. This concept can be utilized during casting and in the coarse grain heat affected zone (CGHAZ) of weldment. In the future, it is foreseen that "Oxide Metallurgy" concept can be applied to other steel grades, such as special steels including nitriding steel and stainless steel.

\section{References}

1. Takamura J, Mizoguchi S (1990) Proceedings of $6^{\text {th }}$ International Iron and Steel Congress, ISIJ, Nagoya, Japan 1: 591-597.

2. Mu W, Jönsson PG, Nakajima K (2017) Recent aspects on the effect of inclusion characteristics on intragranular ferrite formation in steels: a review, High Temp. Process Mater 36(4): 309-325.

3. $\mathrm{Mu}$ W, Jönsson PG, Shibata H, Nakajima K (2016) Inclusion and Microstructure Characteristics in Steels with TiN Additions, Steel Res Int 87(3): 339-348.

4. Mu W, Jönsson PG, Nakajima K (2014) Effect of Sulfur Content on Inclusion and Microstructure Characteristics in Steels with $\mathrm{Ti}_{2} \mathrm{O}_{3}$ and $\mathrm{TiO}_{2}$ additions. ISIJ Int 54(12): 2907-2916.

5. Mu W, Jönsson PG, Nakajima K (2015) $6^{\text {th }}$ International Congress on the Science and Technology of Steelmaking (ICS2015). Beijing, China 2: 767-771.

6. Mu W, Jönsson PG, Nakajima K (2015) Challenges and Transformative Solutions to Sustainable Steelmaking and Casting for EnvironmentFriendly Metallurgical Innovation (CTSSC-EMI), Tokyo, Japan, pp. 6471.

7. Mu W, Shibata H, Hedström P, Jönsson PG, Nakajima K (2016) Ferrite Formation Dynamics, Inclusion Characteristics and Microstructures in Inclusion Engineered Steels with $\mathrm{Ti}_{2} \mathrm{O}_{3}$ and TiN Additions. Metall Mater Trans B, 47B(4): 2133-2147.

8. Mu W, Shibata H, Hedström P, Jönsson PG, Nakajima K (2016) Combination of In-situ Microscopy and Calorimetry to Study Austenite Decomposition in Inclusion Engineered Steels. Steel Res Int 87(1): 1014.

9. Mu W, Jönsson PG, Nakajima K (2016) Prediction of Intragulanular Ferrite Nucleation in Steels with TiN and Ti-oxide Additions, J Mater Sci 51(4): 2168-2180. 
10. Mu W, Mao H, Jönsson PG, Nakajima K (2016) Effect of Carbon Content on the Potency of the Intragranular Ferrite Formation, Steel Res Int 87(3): 311-319.

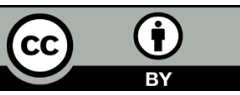

This work is licensed under Creative Commons Attribution 4.0 Licens DOI: 10.19080/JOJMS.2017.01.555570
11. Xuan C, Mu W, Olano ZI, Jönsson PG, Nakajima K (2016) Effect of Ti and $\mathrm{Al}$ Content and the Holding Time on the Inclusion Characteristics in steels with $\mathrm{TiO}_{2}$ Additions, Steel Res Int 87(7): 911-920.

Your next submission with Juniper Publishers
will reach you the below assets
- Quality Editorial service
- Swift Peer Review
- Reprints availability
- E-prints Service
- Manuscript Podcast for convenient understanding
- Global attainment for your research
- Manuscript accessibility in different formats
( Pdf, E-pub, Full Text, Audio)
- Unceasing customer service
Track the below URL for one-step submission
https://juniperpublishers.com/online-submission.php

